\title{
Human as relation: An exploration of the ethics of care
}

\author{
Kira Brunner ${ }^{1}$
}

\begin{abstract}
This essay describes the ethics of care, a philosophical theory originally born out of psychological studies on development. For much of psychological history, women were seen to be 'less developed' on standardized tests of morality. In response, Carol Gilligan produced a study that examined how women's conceptions of moral responsibility differ from men, especially in terms of care, connection, and interdependence. This relationality has been developed into a complex ethical theory which this paper opposes against consequentialism and Kantian ethics; two ethical theories that instead favour impersonality. Further, it is argued that not only is unequal interdependence central to human experience; it is also a natural human drive to care for ourselves and the people closest to us. Ethical theories that oppose this fail to serve their purpose in providing a framework that is possible for humans to follow and must make concessions or subjustifications to avoid complete alienation in their followers. With two case examples, this essay establishes the ethics of care within the psychological development framework and argues for its superiority as compared to impersonal ethical theories.
\end{abstract}

Keywords: Care Ethics, Relational Equality, Feminist Theory.

\footnotetext{
${ }^{1}$ Department of Philosophy, McGill University. Address all correspondence to kira.brunner@mail.mcgill.ca.
} 
For centuries, moral theory has emphasized only the impersonal, abstract, and individual. Is it even possible for a moral theory to act personally, to be sensitive to contexts and relationships? The ethics of care is this very conception and argues that it is not only possible to have such a theory, but moral theories must emphasize relation and context. This essay will outline ethics of care, beginning with its start in psychological development theory and its eventual construction into a unique ethical theory. Using two case studies from consequentialism and Kantian ethics, I will show that the ethics of care is the ideal moral theory, after which I will consider and reject the objection that argues for the 'addition' of care to other mainstream theories. Ultimately, this essay argues for care ethics as the correct version of ethical theory: wherein our most fundamental trait, co-relationality, is emphasized and given moral status.

Care ethics, originally conceptualized as an ethic for women, emerged from Carol Gilligan's feminist text In a Different Voice. She studied under Lawerence Kolhberg, who, outlining a theory of moral development, found women to be morally inferior in issues of individual rights, formal moral theory, and abstract understandings of justice. For Kolhberg, this was a direct reflection of women's cognitive capabilities: they were underdeveloped compared to men (Gilligan 18). In response, Gilligan's own work argued that not only were women just as cognitively capable as men, Kolhberg's poor study design and allmale sample size produced the effect he found. Gilligan found that women had a "distinct moral language" (Gilligan 73) that emphasized care, interdependence, responsibility, context, and avoiding hurt. This was a new development in moral theory, devoid of the impersonal nature that Railton alludes to. Importantly, this new strand of moral theory was not merely theoretical but empirically grounded, "characterized not by gender but theme" (Gilligan 2) - therefore, it is not unique to, or descriptive of all, women - however, its association with women is reflective of the group as a whole. Gilligan argued that women's socialization as caretakers is one possible explanation for this phenomenon.

Following the tradition of Jean Piaget and Lawrence Kohlberg, Gilligan 
outlines the ethics of care in three steps: pre-conventional, conventional, and postconventional. The central tendency of her theory emerged as a balance between selfishness and selflessness. The preconventional phase, typically seen under the age of ten, focuses on individual survival. Self-care and self-preservation are central, and others are excluded from conceptions of morality entirely. This can be summarized as 'what's best for me?'. The conventional stage, beginning in adolescence, is where most people remain in their moral development. It emphasizes goodness as self-sacrifice, thus recognizing the need for responsibility to others as important to ethics. At the time of Gilligan's writing, many moral theories, such as consequentialism, fit into the conventional category. These theories emphasized always doing for others to increase goodness - summed as everyone thinking 'what's best for others?'. Gilligan's final stage, known as the post-conventional, arises after the moral agent recognizes themselves as worthy of care as well. This stage is best described as a morality of 'non-violence,' arising after the revelation that the self and the other are interdependent and inherently connected. The culmination of this theory in the post-conventional stage: 'what's best for us?'.

Since Gilligan, moral philosophers including Annette Baier and Virginia Held have expanded the ethics of care into a unique moral discipline, expanding on Gilligan's primarily psychological theory. Going also by other names such as care ethics or relational ethics, the ethics of care focuses primarily on relationships and the inherent interconnectedness of human beings. Instead of universalizing moral theories such as consequentialism that stress increasing individual goodness, especially for others, care ethics do not hinge on a single 'moral goal' as such. Instead, Gilligan's understanding of women's nurturing relationships can be seen as a model on which to base moral actions. Humans are always interdependent - we begin as babies, needing nurture and care, and typically die as an elder, or in sickness, needing care again. We rely on others to grow our food, build our houses, and clean our water. Much of modern capitalism depends on the exchange of specific goods: increasing our need for 
interdependence more than ever. However, even if one lived off the land completely without help from anyone else, they still received care as an infant. In this way, caring for others becomes the basis for human existence, and therefore, as well, the basis for ethical theory. In general, care ethics then argues that the most morally good actions are the ones that help others fill their basic needs, sustain life and happiness, and avoid or alleviate pain and suffering. Instead of following an action-to-action approach, such as consequentialism or Kantian ethics may prescribe, ethical care actions are ones that span a lifetime, focusing on a general commitment to care and relationships. Since care ethics recognizes humanity's interconnectivity, it emphasizes that we must orient ourselves to the wellbeing of the self as well as others. Taking care of others, in turn, takes care of ourselves.

Perhaps the greatest virtue of care ethics, as opposed to dominant theories such as consequentialism, is its inclusion and value placed on human emotion. Even consequentialist theorists, such as Peter Railton, recognize the need to combat the alienation that follows from focusing entirely on increasing goodness through individual actions. A significant portion of Railton's work "Alienation, Consequentialism, and Morality" discusses the case of Juan, wherein a husband wants to spend money on himself and his wife, and therefore not donate the money to charity. Under consequentialism, how is this justified? Railton produces a sub-theory of consequentialism to justify this act, a husband spending quality time with his wife. Regardless of the validity of this new theory, it is clear that humans have an innate desire to connect with others and caretake ourselves and who we love - care ethics allows for this without creating a sub-theory of other justifications. Emotions are morally valid. This is not to say that care ethics would necessarily allow for a moral justification of, say, murder. Instead, a general commitment to reducing harm, cultivating relationships, and focusing on ourselves, as well as others, has its own inherent moral value. As Railton states himself, "By altering social and political arrangements we can lessen the disruptiveness of moral demands on our lives, and in the long run, achieve better 
results than free-lance good-doing" (Railton 161). However, even in acknowledging this, Railton prefers to 'add' an element of care to consequentialism rather than endorse a theory that does this integrally. By adding this addition, too, Railton undermines the central tenant of consequentialism: by spending money on himself and his wife, he is no longer doing the most good for the most people. Care ethics offers a direct response to consequentialism's alienation problem, without making concessions, and is more accommodating to human nature in this regard.

As a second example, take the case of Maria Von Herbert and Immanuel Kant outlined in Rae Langton's paper "Maria Von Herbert's Challenge to Kant". Through a series of letters, Von Herbert, a devoted follower of Kantian ethics, expresses to Kant the shame and depression she feels after hiding from her partner the fact that she had premarital sex with someone else. Once she tells her partner, he leaves her. Von Herbert knows that telling him was the right thing, morally, to do: if she had lied, she would violate a key aspect of Kantian deontology. However, adhering so strictly to her preferred ethical theory has not provided her with any solace - she is the ideal Kantian moral agent, but her life is empty and meaningless, as Langton states, she is "chilling in nihilism" (Langton 380). Von Herbert feels tension between her choices and her humanity; before she dies, she says in a letter, "I was aware of the honesty friendship demands and at the same time I could see the terribly wounding consequences" (Langton 384). How would care ethics allow for a more complex understanding of Von Herbert's situation? By emphasizing connection, social relationships, harm and oppression, care ethics allows moral agents to morally 'zoom out' and determine the ethical quality of their situation. Care ethicists can consider: what social roles did women play during Von Herbert's time? Did they contribute to the shame she experienced and her partner's decision to leave her? In a highly sexist society, is it ethical for women to act in circumstances of self-preservation, while possibly doing a 'smaller' moral wrong by lying? Care ethics say yes. We must focus on what improves overall happiness, alleviate suffering, and avoid the vast emptiness 
Von Herbert felt when pursuing Kantian ethics.

Although the core of care ethics is convincing, the obvious question arises: why is care necessary as a core component in ethical theory, rather than its integration into mainstream ethical theories? It seems that ideas of commitment to relationships, in general, are outlined by other ethical theories, such as Railton's response. Feminist objectives, too, are sometimes encompassed in other versions of consequentialism, utilitarianism, or even Kantian ethics. After all, these theories depend on rationalism and individual rights. Surely, we are rationally all equal, and therefore these ethical prescriptions would help liberate women, racialized peoples, and all who are oppressed. As well, the focus on a 'feminine' response may perpetuate harmful stereotypes about women, such as that they must act caring, nurturing, and some argue that care could "endorse relegation to the nursery and the kitchen" (Held 15). These are all components of the objection that states care could be an additional layer to traditional conceptions of ethics, while justice, abstractness, and individualism continue to reign in the State and legal matters. As Baier says, perhaps we can "agree on the essential minimum, that is on justice and rights, and let whoever wants to go further and cultivate this more demanding ideal of responsibility and care" (Baier 49).

To unpack the objection proposed by Held, and understand the response, I will refer again to Baier. In "The Need for More Than Justice," Baier argues the development of moral theory must include the care ethic conceptions of dependence, interconnection, antiindividualism, and responsibility. Any theory that does not have these features as central, she argues, is incomplete. Mainstream moral theories, such as Kantian ethics and consequentialism, focus too much on the individual and do not reflect how society truly functions. Baier says on these theories; "None ... do much to ensure that the people who have and mutually respect such rights will have any other relationships to one another than the minimal relationship needed to keep such a 'civil society' going" (Baier 47). In other words, while Kantian ethics may require the bare minimum of relationality, as is shown in Von Herbert's 
anecdote, it is (1) not enough to cultivate true human relationships capable of anything more than emptiness, and (2) is simply inaccurate to how humans actually interact. Moreover, if care is an ethical commitment that only some people follow, it will perpetuate sexist and racist lifestyles and divisions of labour. Women are already relegated to the home, unpaid for their home-work and childcare, and continuing to allow this behaviour enforces exploitation from those who can afford to not care. Care ethics emphasizes that not only is interdependence in human relations fundamental to ethics, but unequal interdependence is central to those human relationships themselves.

The relationship between a caretaker and baby is clearly not an equal one - power dynamics are present since birth. There will never be two people perfectly equal in gender, ability, race, sexuality, or socio-economic power. Power defines our independence, and this relationality defines us - if all of human experience is relationships, and humans define themselves through power structures, the relationality of two humans is never equal. Pretending that these social structures do not exist, or perhaps worse, that they do not matter in ethics (consider the common consequentialist phrase 'all else being equal') abstracts away from true causes of injustice that ethical theories should aim to address. There are very rarely true instances of 'all else being equal' in real life; and even if they do exist, the attention that classical ethicists pay to them through thought experiments inflates their significance. In this way, we can see how models such as consequentialism or deontology that take care ethics to be optional, and only necessary for some, necessitate others' exploitation.

It is a cruel reality that those who will inevitably pick up the labour of care are the same ones that need it most: women, Black people, Indigenous people, people of colour, those with disabilities, other marginalized peoples, and the intersections of these groups. The idea of care as something to 'pick up' or 'put down' at any time is, instead, reflective of the philosophers that originally constructed these ethical ideals. In "Standard Moral Theories from a Feminist Perspective," Hilde Lindemann states "The theories aren't impartial. 
Instead, they favour persons whose social standing, concerns, and occupations look suspiciously like those of well-to-do white men" (Lindemann 93-94). Anyone who continues to advocate for an ethical theory such as consequentialism or Kantian ethics maintains the oppressive systems which people who outlined such theories enforce. The emphasis on individualism and personal rights does not protect against mistreatment; instead, women and marginalized groups are expected to liberate themselves within a system designed to ensure that all of their 'free' choices and rights reinforce their oppression.

This essay has argued for the ethics of care to be taken seriously as an independent moral theory, the only one that emphasizes the innate human trait of relationality and gives it moral worth. It has outlined the beginnings of care ethics through the works of Carol Gilligan, Annette Baier, and Virginia Held. Works from Peter Railton and Rae Langton outline the application of care ethics as the solution to issues seen in consequentialism and Kantian ethics, thus placing it as a superior ethical theory. Finally, the objection that care may be an addition to other theories is considered and rejected, as any theory that does not take seriously the interdependence of humans cannot, in turn, take seriously the oppression it serves to eliminate. We are all "second persons," not punctuated, but produced by others (Lindemann 91). As truly relational beings, our ethics should reflect that. 